\title{
KAJIAN KONSEPTUAL DAYA SAING IKM BATIK DI INDONESIA
}

\author{
Nizar Alam Hamdani \\ nizar_hamdani@uniga.ac.id \\ Fakultas Ekonomi, Universitas Garut
}

\begin{abstract}
ABTRACT
The batik industry in Indonesia is generally a small and medium-sized industry which is a major part of the livelihoods of people in various regions in Indonesia. prior to the monetary crisis in 1997 this small and medium industry had experienced rapid progress. The purpose of this study was to theoretically examine the relationship between variables to create small and medium industry Batik competitiveness. The method used is literature study with the aim of finding a theoretical basis in the problem-solving approach to formulating hypotheses to be tested in the study. The results of this study are firstly that leadership, technology, organizations and learning organizations simultaneously and partially affect knowledge management, leadership, technology, learning organizations and organizations have a relationship between variables, leadership, technology, organizations and learning organizations have a simultaneous and partial effect on innovation, knowledge management has an effect on innovation, innovation has an effect on competitiveness, knowledge management has an effect on competitiveness simultaneously and partially through innovation on competitiveness and knowledge management has an effect on competitiveness simultaneously and partially through innovation on competitiveness
\end{abstract}

Keyword : Competitiveness, Innovation, Knowledge Management, Small and Medium Batik Industry.

\begin{abstract}
ABSTRAK
Industri batik di indonesia umumnya merupakan industri kecil menengah yang menjadi sebagian besar pencaharian masyarakat di berbagai daerah di indonesia. sebelum krisis moneter tahun 1997 industri kecil menengah ini sempat mengalami kemajuanyang pesat. Tujuan penelitian ini adalah untuk mengkaji secara teoritis hubungan antar variabel untuk menciptakan daya saing ikm. Metode yang digunakan adalah studi kepustakaan dengan tujuan menemukan landasan teori dalam pendekatan solusi masalah untuk perumusan hipotesis yang bakal diuji dalam penelitian. Hasil dari kajian tersebut adalah pertama kepemimpinan, teknologi, organisasi dan organisasi pembelajaran secara simultan dan parsial berpengaruh terhadap knowledge management, kepemimpinan, teknologi, organisasi dan organisasi pembelajaran mempunyai hubungan antar variabel, kepemimpinan, teknologi, organisasi dan organisasi pembelajaran berpengaruh secara simultan dan parsial terhadap inovasi, knowledge management berpengaruh terhadap inovasi, inovasi berpengaruh terhadap daya saing, knowledge management berpegaruh secara simultan dan parsial melalui inovasi terhadap daya saing dan knowledge management berpegaruh secara simultan dan parsial melalui inovasi terhadap daya saing
\end{abstract}

\section{Kata Kunci : Daya Saing, Inovasi, IKM Batik, Manajemen Pengetahuan}




\section{PENDAHULUAN}

IKM sampai saat ini telah berkonstribusi sebesar 34,56\% terhadap pertumbuhan industri pengolahan non-migas secara keseluruhan. Angka ini dapat tercapai karena sekitar lebih kurang 3,5 juta unit usaha, yang merupakan $90 \%$ dari total unit usaha adalah industri nasional. Jumlah unit usaha tersebut telah mampu menyerap tenaga kerja sebesar 8,4 juta orang, yang tentunya berdampak pada meningkatnya ekonomi nasional serta mengurangi kemiskinan.

Kecenderungannya IKM yang banyak menyerap tenaga kerja membuat sektor ini juga intensif dalam menggunakan sumberdaya lokal. Banyaknya jumlah orang yang bekerja pada IKM memperlihatkan betapa pentingnya peranan IKM dalam membantu memecahkan masalah pengangguran dan pemerataan distribusi pendapatan. Lokasinya yang banyak di pedesaan membuat pertumbuhan dari IKM ini akan menimbulkan dampak positif terhadap peningkatan jumlah tenaga kerja, pengurangan jumlah kemiskinan, pemerataan dalam distribusi pendapatan, dan pembangunan ekonomi di pedesaan (Simatupang, et al., 1994; Kuncoro 1996). Dengan kata lain, pengembangan IKM merupakan bagian dari strategi pembangunan ekonomi yang pro-poor dan pro-job.

Beberapa pengusaha batik sempat mengalami masa kejayaan. Apalagi pada tahun1980an batik merupakan pakaian resmi yang harus dipakai pada setiap acara kenegaraan ataup acara resmi lainnya. Sehingga mengenalkan dan meningkatkan citra batik didunia internasional pada waktu itu. Ekspor batik Indonesia terbuka luas ke negara-negara Amerika Serikat, Swedia, Jerman, Uni Emirat Arab dan Prancis merupakan negara potensial yang mengincar batik Indonesia. Dalam kurun waktu 5 (lima) tahun terakhir ekspor batik Indonesia dapat digambarkan sebagai berikut :

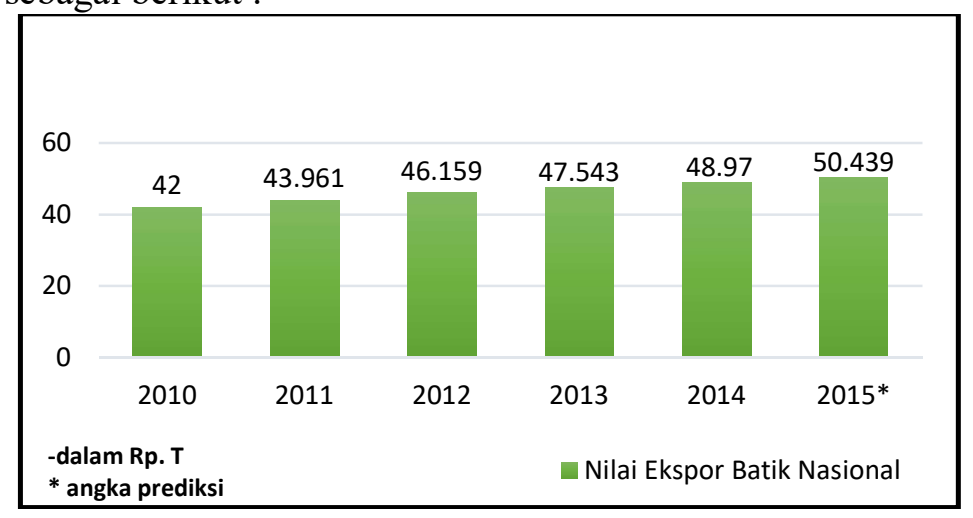

Gambar 1

Data Nilai Ekspor Batik

Sumber : Kemenperin (2017)

Negara pesaing atau sebagai kompetitor batik Indonesia selain Malaysia yang telah mampu menembus pasar dunia, juga datang dari Vietnam, Thailand, Bangladesh, dan China. Untuk itu, kiranya pertimbangan mutu, motif, diskripsi motif dan pemilihan/pemakaian warna yang lebih dapat diterima pasar menjadi pertimbangan dalam rangka penetrasi pasar dunia. 
Tabel 1

Hasil Survei Pendahuluan Daya Saing IKM Batik

\begin{tabular}{|l|l|c|}
\hline No & Daya Saing UKM & $\begin{array}{c}\text { Nilai Rata-Rata } \\
\text { Jawaban } \\
\text { Responden (1-5) }\end{array}$ \\
\hline 1 & Keahlian atau tingkat pendidikan pekerja & 2,88 \\
\hline 2 & keahlian pengusaha & 3,2 \\
\hline 3 & ketersediaan modal & 2,88 \\
\hline 4 & sistem organisasi dan manajemen & 2,76 \\
\hline 6 & ketersediaan teknologi & 2,56 \\
\hline 7 & ketersediaan informasi dan pengetahuan & 2,56 \\
\hline 8 & ketersediaan input-input lainnya seperti energi & 3,48 \\
\hline 9 & bahan baku & 3,64 \\
\hline \multicolumn{2}{|l|}{ Rata-rata } & 2,66 \\
\hline
\end{tabular}

Sumber : Survei Pendahuluan 2018 (25 sampel)

Berdasarkan survei pendahuluan yang dilaksanakan IKM Batik di daerah Bantul, Yogyakarta dan Garut dengan jumlah sampel 25 didapatkan hasil bahwa daya saing secara keseluruhan daya saing IKM masih rendah yaitu 2,66. Faktor Sumberdaya, ketersediaan modal, sistem organisasi dan manajemen, keterseduaan teknologi dan ketersediaan informasi dan pengetahuan masih rendah.

Permasalahan yang dihadapi oleh IKM umumnya terdiri dari dua faktor, baik faktor internal dan eksternal. Faktor internal adalah kegiatan akses pasar dan pemasaran, akses ke bank kapitalisasi, tata kelola dan manajemen, kualitas sumber daya manusia. Faktor eksternal yang tidak iklim yang kondusif bisnis, kurangnya infrastruktur, ekonomi biaya tinggi, dampak dari otonomi daerah, perdagangan bebas, akses terbatas ke informasi. Masalah lain yang dihadapi IKM adalah kurangnya daya saing, dan ini adalah salah satu dari mereka karena kurangnya penelitian di bidang IKM. Penyebab dukungan teknologi informasi yang buruk, karena kurangnya inovasi, akses internet mahal, serta keterbatasan infrastruktur (Santoso et al, 2014; Zuliyati, 2013). Sedangkan hasil penelitian Arfan et al. (2008) mengatakan bahwa faktorfaktor yang mempengaruhi pengembangan kreativitas industri kerajinan batik adalah SDM yang tinggi dan teknologi. Hasil studi dari Simatupang (2008) menunjukkan bahwa masih terdapat beberapa permasalahan di sentra industri batik antara lain rendahnya kreativitas, baik dari segi desain, efisiensi dan kualitas. Faktor-faktor yang mempengaruhi pengembangan kreativitas industri kecil batik pada: (1) variabel SDM kreatif yaitu motivasi, bakat/minat, komunikasi, dan kompetensi; (2) variabel pekerjaan kreatif yaitu pekerjaan, kepemimpinan, dan kewirausahaan; (3) variabel konteks organisasi yaitu kinerja perusahaan, kebijakan, struktur dan budaya organisasi, serta sistem komunikasi; (4) variabel lingkungan yaitu pemberdayaan sumber daya eksternal, teknologi, persaingan, dan peraturan pemerintah; (5) variabel inovasi produk yaitu desain, bahan, alat, dan pemanfaatan limbah batik. Secara keseluruhan, pada semua variabel terdapat faktor-faktor yang mendukung pengembangan kreativitas (Simatupang, 2008) 


\section{KAJIAN PUSTAKA}

Manajemen pengetahuan sebagai dasar penciptaan pengetahuan tidak hanya berlaku untuk perusahaan besar tetapi juga untuk UKM (Desouza \& Awazu, 2006). Meskipun penelitian telah mengungkapkan bahwa penciptaan pengetahuan dan sumber daya manusia masih rendah, tetapi penerapan penciptaan pengetahuan dapat meningkatkan daya saing dan kinerja UKM (Cerchione et al., 2015). Penciptaan pengetahuan dan penguasaan teknologi pada UKM berbeda dengan teori penciptaan pengetahuan yang sering dijumpai di perusahaan besar. Secara teoritis, para ahli biasanya menyarankan bahwa penciptaan pengetahuan dan teknologi begitu hanya berlaku untuk perusahaan besar; Namun secara empiris aplikasi tersebut banyak dijumpai di UKM (Rrustemi, 2011). Juga disarankan bahwa teknologi berperan besar dalam perkembangan UKM (Carr, 2005). Selain itu, Solek-Borowska (2017) berpendapat bahwa manajemen pengetahuan perlu dilakukan dengan baik dibangun untuk mendukung penciptaan pengetahuan di UKM. Penelitiannya juga menunjukkan bahwa organisasi UKM itu datar dan membutuhkan lebih sedikit orang serta penerapan teknologi yang rendahTeknologi informasi adalah salah satu kunci keberhasilan implementasi KM dan memiliki peranan yang tidak terbantahkan (Wong, 2005: 95). Teknologi informasi mengubah cara kita melakukan sesuatu dan menawarkan peluang dan tantangan baru dalam bisnis (Azyabi, 2017; Maghanga, 2017). Saat ini, teknologi informasi salah satu pilar utama pembangunan manusia. Informasi Teknologi harus mampu memberikan nilai tambah bagi masyarakat komunitas dan sangat penting bagi perusahaan non-IT. Teknologi informasi membantu kita dengan informasi pemrosesan. Ini memfasilitasi penggunaan untuk membuat, mengelola, dan bertukar informasi.

Organisasi pembelajaran berpengaruh kepada knowledge manajemen, beberapa menjelaskan bahwa knowledge yang umum dalam perusahaan yang diartikualasikan dengan jelas dan mudah dipahami hal ini dijelaskan oleh Barna (2002), Cross and Baird (2000), Davenport et al. (1998), Ginsberg and Kambil (1999), Jennex and Olfman (2000), Mandviwalla et al. (1998), Sage and Rouse (1999).Berdasarkan beberapa kajian dapat dipetakan perbedaan dan persamaan dengan penelitian terdahulu, sehingga penelitian yang dilaksanakan akan memiliki kebaharuan. Adapun penelitian terdahulu sebagai berikut :

Tabel 2

Penelitiaan Terdahulu

\begin{tabular}{|c|c|c|c|c|c|c|c|}
\hline No & $\begin{array}{l}\text { Nama } \\
\text { Penulis }\end{array}$ & Thn & Judul Penelitian & $\begin{array}{l}\text { Konsep yang } \\
\text { Digunakan }\end{array}$ & Metode & Hasil Penelitian & $\begin{array}{c}\text { Perbedaan dan } \\
\text { Persamaan }\end{array}$ \\
\hline 1 & Nonaka & $\begin{array}{l}1991 \\
1994\end{array}$ & $\begin{array}{l}\text { The knowledge } \\
\text { creating } \\
\text { company }\end{array}$ & $\begin{array}{l}\text { Tacit and explicit } \\
\text { knowledge }\end{array}$ & $\begin{array}{l}\text { Pendekatan yang } \\
\text { digunakan adalah } \\
\text { permodelan }\end{array}$ & $\begin{array}{l}\text { SECI Process of } \\
\text { Knowledge } \\
\text { (socialization, } \\
\text { externalization, } \\
\begin{array}{l}\text { combination, } \\
\text { internalization) }\end{array}\end{array}$ & $\begin{array}{l}\text { Perbedaan } \\
\text { metode } \\
\text { penelitian, } \\
\text { varibael yang } \\
\text { digunakan. } \\
\text { Persamaannya } \\
\text { bahwa Nonaka } \\
\text { sebagai konsep } \\
\text { awal dalam KM } \\
\text { yang digunakan } \\
\text { dalam penelitian }\end{array}$ \\
\hline
\end{tabular}


p-ISSN : 2655-7304

e-ISSN : 6655-8953

\begin{tabular}{|c|c|c|c|c|c|c|c|}
\hline No & $\begin{array}{c}\text { Nama } \\
\text { Penulis }\end{array}$ & Thn & Judul Penelitian & $\begin{array}{c}\text { Konsep yang } \\
\text { Digunakan }\end{array}$ & Metode & Hasil Penelitian & $\begin{array}{c}\text { Perbedaan dan } \\
\text { Persamaan } \\
\end{array}$ \\
\hline 2 & Bhat & 2001 & $\begin{array}{l}\text { Knowledge } \\
\text { management as } \\
\text { an interaction } \\
\text { between } \\
\text { technologies, } \\
\text { techniques and } \\
\text { people. }\end{array}$ & $\begin{array}{l}\text { Tecknologi } \\
\text { merupakan } \\
\text { media untuk } \\
\text { melakukan } \\
\text { transfer } \\
\text { pengetahuan }\end{array}$ & $\begin{array}{l}\text { Pendekatan yang } \\
\text { digunakan } \\
\text { menggunakan } \\
\text { analisis ekperimen }\end{array}$ & $\begin{array}{l}\text { Hasil menunjukan } \\
\text { bahwa perushaan yang } \\
\text { menggunaan teknologi } \\
\text { lebih efektif dalam } \\
\text { mengembangkan } \\
\text { pengetahuan dan } \\
\text { transfer }\end{array}$ & $\begin{array}{l}\text { Perbedaan } \\
\text { metode, } \\
\text { persamaannya } \\
\text { adalah adanya } \\
\text { unsut teknologi } \\
\text { dalam KM }\end{array}$ \\
\hline 3 & $\begin{array}{l}\text { Cerchione } \\
\text { dan Esposito }\end{array}$ & 2015 & $\begin{array}{ll}\text { The Spread } & \text { of } \\
\text { Knowledge } & \\
\text { Management } & \text { in } \\
\text { SMEs: } & \text { A } \\
\text { Scenario } & \text { in } \\
\text { Evolution } & \end{array}$ & $\begin{array}{l}\text { Kontigensi faktor } \\
\text { keberhasilan KM } \\
\text { di Sme, Circital } \\
\text { Faktor serta } \\
\text { Kendala } \\
\text { implementasi } \\
\text { KM }\end{array}$ & Literatur review & $\begin{array}{l}\text { Adanya penerapan } \\
\text { kenowledge } \\
\text { managament dapat } \\
\text { meningkatkan kinerja } \\
\text { bisnis perusahaan }\end{array}$ & $\begin{array}{l}\text { Perbedaan } \\
\text { variabel serta } \\
\text { pendekatan yang } \\
\text { digunakan. } \\
\text { Persamaanya } \\
\text { mengakaji } \\
\text { implementasi }\end{array}$ \\
\hline 4 & $\begin{array}{l}\text { Wong and } \\
\text { Elaine } \\
\text { Aspinwall }\end{array}$ & 2005 & $\begin{array}{l}\text { An empirical } \\
\text { study of the } \\
\text { important factors } \\
\text { for knowledge- } \\
\text { management } \\
\text { adoption in the } \\
\text { SME sector }\end{array}$ & KM initiative & $\begin{array}{l}\text { A survey } \\
\text { instrument } \\
\text { comprising } \\
\text { factors and } 66 \\
\text { elements was } \\
\text { developed. } \\
\text { Through a postal } \\
\text { survey, data were } \\
\text { sought from SMEs } \\
\text { in the UK. A } \\
\text { parallel one was } \\
\text { also administered } \\
\text { to a group of } \\
\text { academics, } \\
\text { consultants and } \\
\text { practitioners in the } \\
\text { KM field in order to } \\
\text { provide a more } \\
\text { holistic view of the } \\
\text { CSFs. }\end{array}$ & $\begin{array}{l}\text { Hasil penelitian } \\
\text { menunjukan bahwa } \\
\text { ktitikal faktor secara } \\
\text { berurutan } \\
\text { berikutt: } \\
\text { 1. management } \\
\text { leadership and support; } \\
\text { 2. culture; 3. strategy } \\
\text { and purpose; } 4 . \\
\text { resources; 5. processes } \\
\text { and activities; } 6 . \\
\text { training and education; } \\
7 . \quad \text { human resource } \\
\text { management; } \\
\text { information } \\
\text { technology; } \\
\text { motivational aids; } 10 . \\
\text { organisational } \\
\text { infrastructure; and } 11 . \\
\text { measurement. }\end{array}$ & $\begin{array}{l}\text { Perbedaan } \\
\text { metode } \\
\text { penelitian, } \\
\text { varibael yang } \\
\text { digunakan. } \\
\text { Persamaannya } \\
\text { bahwa Nonaka } \\
\text { sebagai konsep } \\
\text { awal dalam KM } \\
\text { yang digunakan } \\
\text { dalam penelitian }\end{array}$ \\
\hline 5 & Choochote & 2013 & $\begin{array}{l}\text { Knowledge } \\
\text { Management } \\
\text { Strategyfor } \\
\text { SMEs }\end{array}$ & $\begin{array}{l}\text { IT infrastruktur, } \\
\text { KN software } \\
\text { Tools, Kebijakan } \\
\text { Perusahaan } \\
\text { dalam KM, dan } \\
\text { isue strategis } \\
\text { lainnya }\end{array}$ & $\begin{array}{l}\text { Uji Beda SMEs } \\
\text { yang mengadopsi } \\
\text { KN dan SMEs yang } \\
\text { tidak mengadopsi } \\
\text { Kowledge } \\
\text { Management }\end{array}$ & $\begin{array}{l}\text { The first and most } \\
\text { influential factor is the } \\
\text { SMEs understanding } \\
\text { of the knowledge } \\
\text { management strategy. } \\
\text { The second factor } \\
\text { which most likely had } \\
\text { an effect on the results } \\
\text { of the study was the } \\
\text { state of the economy at } \\
\text { the time of conducting } \\
\text { the study }\end{array}$ & $\begin{array}{l}\text { Perbedaannya } \\
\text { adalah dari } \\
\text { metode } \\
\text { penelitian, } \\
\text { variabel, sampel. } \\
\text { Persamaany } \\
\text { adanya variabel } \\
\text { KM dan IT }\end{array}$ \\
\hline 6 & $\begin{array}{l}\text { Neeru } \\
\text { Mundra, } \\
\text { Karishma } \\
\text { Gulati and } \\
\text { Renu } \\
\text { Vashisth }\end{array}$ & 2011 & $\begin{array}{l}\text { Knowledge } \\
\text { Management and } \\
\text { (KM) } \\
\text { Innovation: } \\
\text { Empirical } \\
\text { Evidences from } \\
\text { the Indian IT } \\
\text { Sector Achieving } \\
\text { Competitive } \\
\text { Advantage } \\
\text { Through }\end{array}$ & $\begin{array}{l}\text { Penelitian ini } \\
\text { dilakukan } \\
\text { terhadap pekerja } \\
\text { di bidang IT pada } \\
15 \text { perusahaan } \\
\text { yang menerapkan } \\
\text { knowledge } \\
\text { management, dan } \\
\text { menggunakan } \\
\text { prosentase, chart } \\
\text { dan } Z \text { test untuk } \\
\text { pengujian } \\
\text { hipotesis. }\end{array}$ & Deskriptif & $\begin{array}{lr}\text { Hasil } & \text { penelitian } \\
\text { menunjukkan } & \text { bahwa } \\
\text { KM dan inovasi yang } \\
\text { merupakan salah satu } \\
\text { indikator dari orientasi } \\
\text { kewirausahaan } \\
\text { merupakan hal yang } \\
\text { penting } & \text { untuk } \\
\text { mencapai } & \text { keunggulan } \\
\text { bersaing. } & \text { KM } \\
\text { mempengaruhi } & \text { inovasi } \\
\text { tetapi } & \text { tidak } \\
\text { sebaliknya. } & \text { Inovasi } \\
\text { memberikan } & \text { cara baru } \\
\text { mengelola } & \text { knowledge } \\
\text { dengan } & \text { teknologi } \\
\text { sebagai } & \text { fasilitator. } \\
\text { Interaksi } & \text { karyawan }\end{array}$ & $\begin{array}{l}\text { Perbedaannya } \\
\text { adalah dari } \\
\text { metode } \\
\text { penelitian, } \\
\text { variabel, sampel. } \\
\text { Persamaany } \\
\text { adanya variabel } \\
\text { KM dan IT }\end{array}$ \\
\hline
\end{tabular}


p-ISSN : 2655-7304

e-ISSN : 6655-8953

\begin{tabular}{|c|c|c|c|c|c|c|c|}
\hline No & $\begin{array}{c}\text { Nama } \\
\text { Penulis }\end{array}$ & Thn & Judul Penelitian & $\begin{array}{c}\text { Konsep yang } \\
\text { Digunakan }\end{array}$ & Metode & Hasil Penelitian & $\begin{array}{c}\text { Perbedaan dan } \\
\text { Persamaan } \\
\end{array}$ \\
\hline & & & & & & $\begin{array}{l}\text { menciptakan } \\
\text { knowledge dan } \\
\text { mempromosikannya. } \\
\text { Perusahaan harus fokus } \\
\text { pada pengembangan } \\
\text { kapabilitas yang } \\
\text { dinamis (dynamics of } \\
\text { capabilities } \\
\text { development). }\end{array}$ & \\
\hline 7 & $\begin{array}{ll}\text { Jeffrey } & \text { E. } \\
\text { McGee, } & \\
\text { Leonard } & \text { G. } \\
\text { Love, } & \\
\begin{array}{l}\text { Michael } \\
\text { Rubach }\end{array} & \text { J. }\end{array}$ & 2011 & $\begin{array}{l}\text { Small } \\
\text { Independent } \\
\text { Retailers: } \\
\text { Lessons from the } \\
\text { Neighborhood } \\
\text { Drugstore of } \\
\text { Sources } \\
\text { Competitive } \\
\text { Advantage For }\end{array}$ & $\begin{array}{l}\text { Penelitian ini } \\
\text { dilakukan pada } \\
\text { pedagang eceran } \\
\text { dalam bidang } \\
\text { obat-obatan, dan } \\
\text { tidak meneliti } \\
\text { variabel sumber } \\
\text { daya dan variabel } \\
\text { kapabilitas } \\
\text { distingtif untuk } \\
\text { mencapai } \\
\text { keunggulan } \\
\text { bersaing }\end{array}$ & Path Analisis & 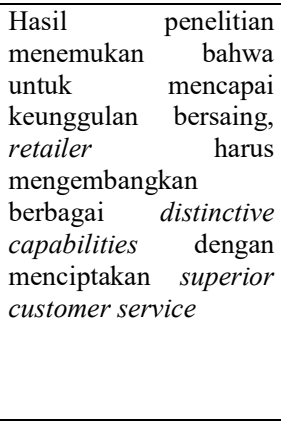 & $\begin{array}{l}\text { Perbedaan } \\
\text { analisis yang } \\
\text { digunakan adalah } \\
\text { analisis jalur } \\
\text { sedangkan } \\
\text { peneliti } \\
\text { menggunakan } \\
\text { SEM, perbedaan } \\
\text { industri UKM } \\
\text { serta perbedaan } \\
\text { ouput }\end{array}$ \\
\hline 8 & $\begin{array}{l}\text { Zdenek } \\
\text { Molnar1 , } \\
\text { Hai Hang } \\
\text { Nguyen2, } \\
\text { Lubor } \\
\text { Homolka2, } \\
\text { Roderick J } \\
\text { Macdonald3 }\end{array}$ & 2011 & $\begin{array}{l}\text { Knowledge } \\
\text { Management as a } \\
\text { solution for the } \\
\text { shortage } \\
\text { competent of } \\
\text { employees in } \\
\text { SMEs at the } \\
\text { developing } \\
\text { countr }\end{array}$ & $\begin{array}{l}\text { Fokus kepada } \\
\text { SDM meliputi } \\
\text { HR turnover, } \\
\text { Kemampuan } \\
\text { sharing }\end{array}$ & $\begin{array}{l}\text { Fuzzy method, chi- } \\
\text { square test were } \\
\text { employed to } \\
\text { analyze collected } \\
\text { data. Linear } \\
\text { Discriminant } \\
\text { Analysis (LDA) } \\
\text { was also used to } \\
\text { classify the classes } \\
\text { of firms in this } \\
\text { research. }\end{array}$ & $\begin{array}{l}\text { Hasil menunjukan tidak } \\
\text { ada pengaruh antara } \\
\text { turnover HR dengan } \\
\text { produktivitas UKM, } \\
\text { sedangkan kemampuan } \\
\text { berbagai pengetahuan } \\
\text { sangat mempengaruhi } \\
\text { teradap produktivitas. }\end{array}$ & $\begin{array}{l}\text { Perbedaan } \\
\text { analisis } \\
\text { menggunakan } \\
\text { model fuzzy } \\
\text { (matematika) } \\
\text { sedangkan } \\
\text { persamaannya } \\
\text { adalah adanya } \\
\text { knowledge } \\
\text { sharing sebagai } \\
\text { bagian KM }\end{array}$ \\
\hline 10 & $\begin{array}{l}\text { Julien Enre- } \\
\text { Piere \& } \\
\text { Ramangalah } \\
\text { y Charles }\end{array}$ & 2003 & $\begin{array}{l}\text { Competitive } \\
\text { strategy and } \\
\text { performance of } \\
\text { exporting SMEs: } \\
\text { An empirical } \\
\text { investigation of } \\
\text { the impact of } \\
\text { their export } \\
\text { information } \\
\text { search and } \\
\text { competencies. } \\
\text { Meneliti } \\
\text { bagaimana } \\
\text { pengaruh } \\
\text { Information } \\
\text { search and } \\
\text { competencies }\end{array}$ & $\begin{array}{l}\text { Meneliti } \\
\text { bagaimana } \\
\text { pengaruh } \\
\text { Information } \\
\text { search and } \\
\text { competencies } \\
\text { terhadap } \\
\text { keunggulan } \\
\text { bersaing sebagai } \\
\text { intervening } \\
\text { variabel dan } \\
\text { implikasinya } \\
\text { terhadap kinerja } \\
\text { ekspor. }\end{array}$ & $\begin{array}{l}\text { Menggunakan } \\
\text { statistik deskriptif } \\
\text { untuk } \\
\text { mendeskripsikan } \\
\text { karakteristik } \\
\text { sample dan untuk } \\
\text { pengujian hipotesis } \\
\text { digunakan PLS }\end{array}$ & $\begin{array}{lr}\text { Hasil penelitian } \\
\text { menemukan adanya } \\
\text { hubungan antara } \\
\text { Information search and } \\
\text { competencies terhadap } \\
\text { kinerja industri kecil } \\
\text { menengah yang } \\
\text { melakukan ekspor }\end{array}$ & $\begin{array}{l}\text { Perbedaan } \\
\text { metode } \\
\text { penelitian, } \\
\text { varibael yang } \\
\text { digunakan. } \\
\text { Persamaannya } \\
\text { bahwa Nonaka } \\
\text { sebagai konsep } \\
\text { awal dalam KM } \\
\text { yang digunakan } \\
\text { dalam penelitian }\end{array}$ \\
\hline 11 & $\begin{array}{l}\text { Zieba and } \\
\text { Zieba }\end{array}$ & 2014 & $\begin{array}{l}\text { Knowledge } \\
\text { Management } \\
\text { Critical Success } \\
\text { Factor and the } \\
\text { Innovation of } \\
\text { KIBS Companies }\end{array}$ & $\begin{array}{l}\text { Tujuan Penelitian } \\
\text { Mengukur } \\
\text { kritikal faktor2 } \\
\text { KM dan Inovasi } \\
\text { pada perusahaan } \\
\text { KIBS di } \\
\text { Polandia. } \\
\text { Adapun konsep } \\
\text { theory yang } \\
\text { digunakan yaitu } \\
\text { knowledge } \\
\text { creation, } \\
\text { knowledge } \\
\text { sharing, team } \\
\text { workingh, } \\
\text { profesional }\end{array}$ & $\begin{array}{lr}\text { Perusahaan } & \text { yang } \\
\text { dijadikan } & \text { sampel } \\
\text { sebanyak } & 400 \\
\text { perusahaan } & \text { SMEs } \\
\text { KIBS. } & \text { Untuk } \\
\text { mengetahui } & \text { CSF } \\
\text { maka digunakan } \\
\text { Chi-Squared }\end{array}$ & $\begin{array}{l}\text { Hasil penelitian } \\
\text { menunjukan bahwa } \\
\text { organisasi yang kuat } \\
\text { dalam kepemimpinan } \\
\text { dengan didukung oleh } \\
\text { manajemen yang solid } \\
\text { dengan pegawai yang } \\
\text { termotivasi lebih } \\
\text { inovatif dibandingkan } \\
\text { dengan pesainnya }\end{array}$ & $\begin{array}{l}\text { Perbedaanya } \\
\text { terletak pada } \\
\text { metode } \\
\text { (verifikatif) } \\
\text { sedangan Zieba } \\
\text { lebih kepada } \\
\text { deskriptif. } \\
\text { Persamaan } \\
\text { dimensi yang } \\
\text { digunakan KM } \\
\text { hampir sama }\end{array}$ \\
\hline
\end{tabular}


p-ISSN : 2655-7304

e-ISSN : 6655-8953

\begin{tabular}{|c|c|c|c|c|c|c|c|}
\hline No & $\begin{array}{l}\text { Nama } \\
\text { Penulis }\end{array}$ & Thn & Judul Penelitian & $\begin{array}{c}\text { Konsep yang } \\
\text { Digunakan }\end{array}$ & Metode & Hasil Penelitian & $\begin{array}{c}\text { Perbedaan dan } \\
\text { Persamaan }\end{array}$ \\
\hline & & & & $\begin{array}{l}\text { development dan } \\
\text { innovation } \\
\text { performance }\end{array}$ & & & \\
\hline 12 & $\begin{array}{l}\text { Evangelista, } \\
\text { Esposito, } \\
\text { Lauro and } \\
\text { Raffa }\end{array}$ & 2010 & $\begin{array}{l}\text { The Adoption of } \\
\text { Knowledge } \\
\text { Management } \\
\text { System in Small } \\
\text { Firm }\end{array}$ & $\begin{array}{l}\text { Tujuan penelitian } \\
\text { ini adalah untuk } \\
\text { mengukur } \\
\text { manfaat } \\
\text { penerapan KM di } \\
\text { SME yang } \\
\text { menggunakan } \\
\text { high-tech dengan } \\
\text { menggunakan } \\
\text { konsep } \\
\text { Knowledge } \\
\text { Management } \\
\text { System }\end{array}$ & $\begin{array}{l}\text { Metodologi yang } \\
\text { digunakan adalah } \\
\text { deskriptif } \\
\text { menggunakan studi } \\
\text { kepustakaan dan } \\
\text { kuesioner } \\
\text { terstruktur yang } \\
\text { telah divalidasi } \\
\text { melalui FGD }\end{array}$ & 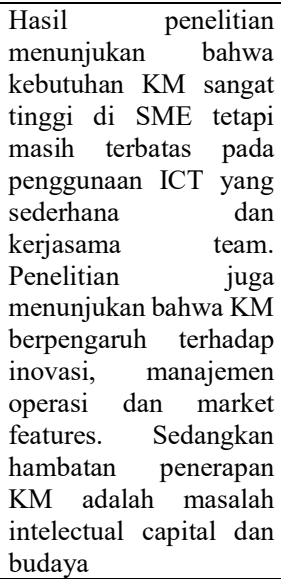 & $\begin{array}{l}\text { Perbedaannya } \\
\text { adalah metode, } \\
\text { persamaannya } \\
\text { adalah mengkaji } \\
\text { penerapan KM di } \\
\text { SMEs }\end{array}$ \\
\hline 13 & Dudek & 2013 & $\begin{array}{l}\text { Evaluation Of } \\
\text { Knowledge } \\
\text { management in } \\
\text { Small and } \\
\text { Medium-Sized } \\
\text { Enterprises }\end{array}$ & $\begin{array}{l}\text { Melakukan } \\
\text { Evaluasi } \\
\text { terhadap SMEs } \\
\text { mengenai } \\
\text { penerapan KM. } \\
\text { Terdapat lima } \\
\text { tahap konsep } \\
\text { yang digunakan } \\
\text { untuk } \\
\text { mengevaluasi } \\
\text { yaitu dengan } \\
\text { tahap 0 Chaotic } \\
\text { knowledge, tahap } \\
1 \text { low awareness } \\
\text { of knowledge, } \\
\text { tahap } 2 \text { Moderate } \\
\text { Knowledge, } \\
\text { Tahap } 3 \text { Medium } \\
\text { Level of KM, } \\
\text { Tahap } 4 \text { Efficient } \\
\text { KM dan tahap 5 } \\
\text { Full Comprehensive } \\
\text { and integrated } \\
\text { KM }\end{array}$ & $\begin{array}{l}\text { Metodologi yang } \\
\text { digunakan adalah } \\
\text { metode deskriptif } \\
\text { dengan } \\
\text { menggunakan } \\
\text { kuesioner dengan } \\
\text { sampel 142 SMEs }\end{array}$ & 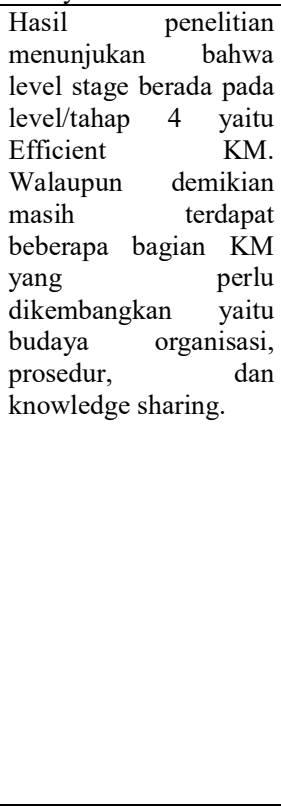 & $\begin{array}{l}\text { Perbedaanya } \\
\text { terletak pada } \\
\text { metode } \\
\text { (verifikatif) } \\
\text { sedangan Dudek } \\
\text { lebih kepada } \\
\text { deskriptif. } \\
\text { Persamaannya } \\
\text { dimensi yang } \\
\text { digunakan KM } \\
\text { hampir sama }\end{array}$ \\
\hline 14 & $\begin{array}{l}\text { Alawneh, } \\
\text { Abuali dan } \\
\text { almarabeh }\end{array}$ & 2009 & $\begin{array}{l}\text { The Role of } \\
\text { Knowledge } \\
\text { Management in } \\
\text { Enhancing the } \\
\text { Competitiveness } \\
\text { of Small and } \\
\text { Medium-Sized } \\
\text { Enterprises } \\
\text { (SMEs) }\end{array}$ & $\begin{array}{l}\text { Capture, } \\
\text { Creation, } \\
\text { Cidofication, } \\
\text { Communication } \\
\text { and } \\
\text { Capitalization } \\
\text { (5C.s) }\end{array}$ & $\begin{array}{l}\text { Studi Literatur } \\
\text { dengan pendekatan } \\
\text { model } 5 \mathrm{Cs}\end{array}$ & $\begin{array}{l}\text { Hasil penelitian } \\
\text { menunjukan bahwa } \\
\text { model 5Cs sangat tepat } \\
\text { digunakan untum SME } \\
\text { dan dapat membrikan } \\
\text { dampak yang sangat } \\
\text { besar bagi peningkatan } \\
\text { daya saing }\end{array}$ & $\begin{array}{l}\text { Perebdaan } \\
\text { metode, } \\
\text { sedangkan } \\
\text { persamaannya } \\
\text { peneliti } \\
\text { menggunakan } 4 \\
\text { Cs dan Alawneh } \\
\text { 5Cs }\end{array}$ \\
\hline 15 & $\begin{array}{l}\text { Megdadi, } \\
\text { Sukkar, } \\
\text { Hammouri }\end{array}$ & 2012 & $\begin{array}{l}\text { Factors and } \\
\text { benefit of } \\
\text { Knowledge } \\
\text { Management } \\
\text { Practices by } \\
\text { SMEs im Irbed } \\
\text { District of Jordan } \\
: \text { An Empirical } \\
\text { Study }\end{array}$ & $\begin{array}{l}\text { Konsep yang } \\
\text { digunakan untuk } \\
\text { mengukur } \\
\text { Kepentingan } \\
\text { Implementasi } \\
\text { KM di SME } \\
\text { terdapat } 11 \text { faktor } \\
: \text { yaitu } \\
\text { Organizational } \\
\text { Leadership } \\
\text { Support, }\end{array}$ & $\begin{array}{l}\text { Menganalisis } \\
\text { Sebelas Fktor yang } \\
\text { Penting dalam } \\
\text { Implementasi KM } \\
\text { di SMEs. Dengan } \\
\text { pendekatan T-Test } \\
\text { Analysis }\end{array}$ & $\begin{array}{lrr}\text { Hasil } & \text { penelitian } \\
\text { menunjukan } & \text { kesebelas } \\
\text { faktor tersebut } & \text { sangat } \\
\text { pentng } & & \text { dalam } \\
\text { penerapan } & & \text { KM } \\
\text { dibuktikan } & & \text { dengan } \\
\text { tingkat } & \text { signifikansi } \\
\text { kurang dari } & 0,05 . \\
\text { Sedangkan } & \text { Benefit } \\
\text { tertinggi } & & \text { dalam } \\
\text { peneraan } & \text { KM } & \text { adalah }\end{array}$ & $\begin{array}{l}\text { Perbedaanya } \\
\text { kalau Magdadi } \\
\text { melakuka } \\
\text { analisis faktor } \\
\text { sedangkan ini } \\
\text { penelitian model } \\
\text { menguji verifikatif. } \\
\text { secara verifan } \\
\text { Persamaannya } \\
\text { menggunakan } \\
\text { variabel }\end{array}$ \\
\hline
\end{tabular}


p-ISSN : 2655-7304

e-ISSN : 6655-8953

\begin{tabular}{|c|c|c|c|c|c|c|c|}
\hline No & $\begin{array}{l}\text { Nama } \\
\text { Penulis }\end{array}$ & Thn & Judul Penelitian & $\begin{array}{c}\text { Konsep yang } \\
\text { Digunakan }\end{array}$ & Metode & Hasil Penelitian & $\begin{array}{c}\text { Perbedaan dan } \\
\text { Persamaan }\end{array}$ \\
\hline & & & & $\begin{array}{l}\text { Organizational } \\
\text { Culture, } \\
\text { Organizational } \\
\text { Resources, } \\
\text { Information } \\
\text { Technology, } \\
\text { Human } \\
\text { Resources } \\
\text { Management, } \\
\text { Strategy and } \\
\text { Purposes, } \\
\text { Motivational } \\
\text { Aids, Process and } \\
\text { Activities, } \\
\text { Trainning and } \\
\text { Education, } \\
\text { Organizational } \\
\text { Infrastructure } \\
\text { dan } \\
\text { Measurement. }\end{array}$ & & $\begin{array}{l}\text { High standar of } \\
\text { organization } \\
\text { performance dengan } \\
\text { frequency } 32 \text { dan } \\
\text { benefit terendah adalah } \\
\text { it provide business } \\
\text { enterprises }\end{array}$ & $\begin{array}{l}\text { kepemimpinan, } \\
\text { teknologi dan LO }\end{array}$ \\
\hline 16 & $\begin{array}{l}\text { Valkokari } \\
\text { dan Helander }\end{array}$ & 2007 & $\begin{array}{l}\text { Knowledge } \\
\text { management in } \\
\text { different types of } \\
\text { strategic SME } \\
\text { networks }\end{array}$ & $\begin{array}{l}\text { Organizational } \\
\text { Learning dan } \\
\text { Technology Bsed }\end{array}$ & Literatur Studi & $\begin{array}{lr}\text { Hasil } & \text { penelitian } \\
\text { menunjukan } & \text { bahwa } \\
\text { strategi KM } & \text { SMEs } \\
\text { ditunjukan oleh strategi } \\
\text { pembelajaran } \\
\text { teknologi }\end{array}$ & $\begin{array}{l}\text { Perbedaan dari } \\
\text { segi metode } \\
\text { penelitian, dan } \\
\text { variabel } \\
\text { penelitian. } \\
\text { Persamaannya } \\
\text { terdapat unsur } \\
\text { knowledge } \\
\text { sharing sebagai } \\
\text { basic dari } \\
\text { technologi } \\
\text { maupun LO }\end{array}$ \\
\hline 17 & Salojärvi & 2004 & $\begin{array}{l}\text { Knowledge } \\
\text { Management and } \\
\text { Growth in } \\
\text { Finnish SMEs }\end{array}$ & $\begin{array}{l}\text { Konsep yang } \\
\text { digunakan } \\
\text { pertumbuhan, } \\
\text { ITdaya saing, } \\
\text { ketertarikan KM, } \\
\text { customer service } \\
\text { personal, Human } \\
\text { Capital }\end{array}$ & $\begin{array}{l}\text { Studi survei } 180 \\
\text { SME, dengan skala } \\
\text { likert memetakan } \\
\text { SMEs (cluster) ke } \\
\text { dalam gambar } \\
\text { pertumbuhan } \\
\text { SMEs serta posisi } \\
\text { SMEs }\end{array}$ & $\begin{array}{l}\text { Hasil meninjukan } \\
\text { cluster terhadap SMEs } \\
\text { berdasarkan variabel } \\
\text { yang digunakan serta } \\
\text { posisi pertumbuhan } \\
\text { tinggi atau rendah }\end{array}$ & $\begin{array}{l}\text { Perbedaanya } \\
\text { penelitian ini } \\
\text { mengelompokan } \\
\text { UKM, kemudian } \\
\text { variabel yang } \\
\text { berbeda. } \\
\text { Persamaannya } \\
\text { ada unsur IT yang } \\
\text { digunakan }\end{array}$ \\
\hline 18 & Nunes et al & 2006 & $\begin{array}{l}\text { Knowledge } \\
\text { management } \\
\text { issues in } \\
\text { knowledge- } \\
\text { intensive SMEs }\end{array}$ & $\begin{array}{l}\text { Proses Tacit and } \\
\text { explicit } \\
\text { knowledge }\end{array}$ & $\begin{array}{l}\text { Pendekatan } \\
\text { kualitatif (case } \\
\text { study) }\end{array}$ & $\begin{array}{l}\text { Hasil menunjukan } \\
\text { bahwa penggunaan KM } \\
\text { dapat meningkatkan } \\
\text { daya saing. Oleh karena } \\
\text { itu penerapan KM } \\
\text { sangat diperlukan }\end{array}$ & $\begin{array}{l}\text { Perbedaan } \\
\text { metodelogi. } \\
\text { Sedangkan } \\
\text { persamaannya } \\
\text { adalah konsep } \\
\text { knowledge } \\
\text { management } \\
\text { yang digunakan }\end{array}$ \\
\hline 19 & $\begin{array}{l}\text { Kevin C. } \\
\text { Desouza and } \\
\text { Yukika } \\
\text { Awazu }\end{array}$ & 2006 & $\begin{array}{l}\text { Knowledge } \\
\text { management at } \\
\text { SMEs: five } \\
\text { peculiarities }\end{array}$ & $\begin{array}{l}\text { The dominance } \\
\text { of socialization in } \\
\text { the SECI cycle, } \\
\text { Common } \\
\text { knowledge, } \\
\text { Knowledge loss: } \\
\text { a problem, } \\
\text { Exploitation of } \\
\text { external sources } \\
\text { of knowledge, } \\
\text { People centered } \\
\text { knowledge } \\
\text { management - } \\
\text { technology in the } \\
\text { background }\end{array}$ & $\begin{array}{l}\text { Pendekatan } \\
\text { deskrptif dengan } \\
\text { kuesioner terhadap } \\
25 \text { SMEs }\end{array}$ & $\begin{array}{l}\text { Hasil menunjukan } \\
\text { bahwa pengelolaan KM } \\
\text { di SMEs berbeda } \\
\text { dengan implementasi } \\
\text { KM di perusahaan besar }\end{array}$ & $\begin{array}{l}\text { Perbedaan } \\
\text { metode yang } \\
\text { digunakan serta } \\
\text { perbedaan } \\
\text { varibael, } \\
\text { persamaannya } \\
\text { mengakaji } \\
\text { penerapan KM di } \\
\text { UKM }\end{array}$ \\
\hline 20 & $\begin{array}{l}\text { Rahmatollah } \\
\text { Gholipour 1, } \\
\text { Gholamreza }\end{array}$ & 2010 & $\begin{array}{l}\text { Explanation of } \\
\text { knowledge } \\
\text { management }\end{array}$ & $\begin{array}{l}\text { Kosnep yang } \\
\text { digunakan adalah } \\
\text { struktur, }\end{array}$ & $\begin{array}{l}\text { Pendekatan } \\
\text { kuantitatif }\end{array}$ & $\begin{array}{lr}\text { Hasil } & \text { menunjukan } \\
\text { bahwa } & \text { teknologi, } \\
\text { strukturm } & \text { people dan }\end{array}$ & $\begin{array}{l}\text { Perbedaannya } \\
\text { adalah variabel } \\
\text { yang digunakan }\end{array}$ \\
\hline
\end{tabular}




\begin{tabular}{|c|c|c|c|c|c|c|c|}
\hline No & $\begin{array}{l}\text { Nama } \\
\text { Penulis }\end{array}$ & Thn & Judul Penelitian & $\begin{array}{c}\text { Konsep yang } \\
\text { Digunakan }\end{array}$ & Metode & Hasil Penelitian & $\begin{array}{c}\text { Perbedaan dan } \\
\text { Persamaan }\end{array}$ \\
\hline & $\begin{array}{l}\text { Jandaghi } 1 * \\
\text { and Seyed } \\
\text { Ali Akbar } \\
\text { Hosseinzade } \\
\text { h } 2\end{array}$ & & $\begin{array}{l}\text { enabler as a latent } \\
\text { variable: A case } \\
\text { study of SMEs in } \\
\text { Iran }\end{array}$ & $\begin{array}{l}\text { teknologi, poeple } \\
\text { dan budaya }\end{array}$ & & 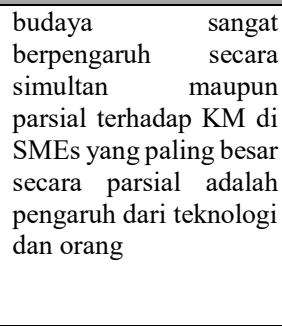 & $\begin{array}{l}\text { serta model } \\
\text { penelitian } \\
\text { persamaannya } \\
\text { menggunakan } \\
\text { alat SEM serta } \\
\text { terdapat variabel } \\
\text { yang sama yaitu } \\
\text { teknologi dan } \\
\text { struktur } \\
\text { organisasi }\end{array}$ \\
\hline
\end{tabular}

\section{METODE}

Metode penelitian yang digunakan adalah penelitian kepustakaan yang diambil dari sumber sumber jurnal, buku referensu serta data pendukung. Sumber pustaka tersebut kemudian di olah melalui table, deskripsi, serta dengan mengaitkan antar sumber referensi yang ada. Adapun sumber kepustakaan focus kepada 3 aspek yaitu knowledge management, inovasi dan daya saing serta konseptual faktor yang mempengaruhi daya saing.

\section{HASIL PENELITIAN DAN PEMBAHASAN}

\section{Pengaruh Teknologi Terhadap Knowledge Management}

Adopsi teknologi adalah sangat dibutuhkan untuk mendukung kinerja dan daya saing UKM. Penggunaan informasi Teknologi memegang peranan yang sangat besar, apalagi jika didukung oleh kebijakan pemerintah yang mendukung sektor teknologi (Raf, 2000). Cerchione et al. (2015) menyatakan bahwa penggunaan TI memberikan dukungan untuk strategi manajemen berkaitan dengan aspek komunikasi, akses informasi, pengambilan keputusan, manajemen data dan manajemen pengetahuan dalam suatu organisasi. TI bisa menjadi kekuatan strategis dan alat organisasi yang menguntungkan aspek promosi dan daya saing (Carr, 2005). ITU membantu organisasi bisnis mengurangi biaya dan meningkatkan kemampuan mereka untuk berkoordinasi dengan pihak luar. Di era ekonomi berbasis pengetahuan saat ini, penting bagi UKM untuk mengadopsi TI karena memungkinkan mereka untuk memberikan layanan yang lebih baik dan kompetitif (Apulu \& Latham, 2011). Kewirausahaan tidak berlaku hanya untuk perusahaan besar tapi juga UKM. Kewirausahaan adalah perilaku yang didasarkan pada konsep dan gagasan Setiap orang yang berani membuat keputusan berani dan secara aktif siap menghadapi masalah mampu melakukannya menjadi seorang pengusaha (Drucker, 1985).

\section{Pengaruh Teknologi Terhadap Inovasi}

Adanya teknologi melalui pemanfaatkan ICT dapat memberikan dampak yang signifikan terhadap asimilasi dari sebuah Inovasi, (Kenneth L Kraemer, Xu 2006) dan (Abrahamson 1991). Teknologi dikelola dengan baik dapat meningkatkan inovasi di UKM/SMEs dalam persaungan (de Vrande et al , 2009), Koruna (2004).

\section{Pengaruh Teknologi Terhadap Daya Saing}

Penerapan teknologi yang tepat serta pemanfaatan software dan hardware dapat memberikan manfaat bagi SMEs dalam peningkatan daya saing yang akhirnya dapat meningkatkan kinerja perusahaan dan pertumbuhan ekonomi (Sigh et al, 2008), Blackwell, P., Shehab, E.M. and Kay, J.M. (2006). Teknologi yang dibangun oleh riset dan pengembangan 
p-ISSN : 2655-7304

e-ISSN : 6655-8953

yang kuat akan menompang terhadap kemampuan perusahaan kecil dan menengah dalam persaingan industri di UK (Hoffman et al, 1998), (Calori, 1990)

\section{Pengaruh Organisasi Pembelajar Terhadap Knowledge Management}

Organisasi pembelajaran berpengaruh kepada knowledge manajemen, beberapa menjelaskan bahwa knowledge yang umum dalam perusahaan yang diartikualasikan dengan jelas dan mudah dipahami hal ini dijelaskan oleh Barna (2002), Cross and Baird (2000), Davenport et al. (1998), Ginsberg and Kambil (1999), Jennex and Olfman (2000), Mandviwalla et al. (1998), Sage and Rouse (1999)

Penelitian yang dilakukan oleh Aydin dan Ceylan (2009) menunjukkan bahwa kapasitas Organizational Learning dapat menjelaskan $65 \%$ total variance dari variabel Organizational Effectiveness. Tiwana (2004) dalam Zeng, et al. (2009) menyatakan bahwa integrasi pengetahuan dapat menyebabkan efektivitas pengembangan produk, mengurangi kepadatan cacat, garansi menurunkan cacat, dan meningkatkan efisiensi. Chang dan Lee (2007:1563) menegaskan pentingnya membangun organisasi pembelajaran. Organisasiorganisasi bisnis mulai menyadari fakta bahwa pengetahuan akan menjadi sumberdaya utama bagi organisasi bisnis dalam membangun kompetensi intinya. Organisasiorganisasi ini juga mulai menggunakan prinsipprinsip inti dalam organisasi pembelajar dengan memberikan perhatian pada pengakumulasian pengetahuan dan sikap pembelajar untuk meningkatkan kemampuan organisasi untuk bertumbuh dan berinovasi.

\section{Pengaruh LO terhadap Daya Saing}

Sistem keterbukaan dan Komitmen manajemen dalam organisasi akan membentuk daya saing SMEs (Ismail, 2013), Hal tersebut merupakan bagian dari kepercayaan internal oragnisasi (Thorgren, S., \& Wincent, J., 2011) yang dapat membentuk kepercayaan sehingga berdampak pada daya saing. Hal tersebut menurut (Herath dan Mahmood, 2013) merupakan bagian dari strategi organisasi dengan intrumen LO untuk mendukung terhadap daya saing SMEs.

\section{Pengaruh Kepemimpinan Terhadap Knowledge Management}

Hasanali (2002) mengidentifikasi beberapa faktor penentu keberhasilan implementasi manajemen pengetahuan pada sebuah organisasi yaitu kepemimpinan. Perhatian pimpinan/manajer adalah pada implikasi manajemen perubahan yang terkait dengan kemampuan untuk meyakinkan dan mempengaruhi orang-orang untuk meyakinkan unit bisnis yang ada untuk berbagi pengetahuan dengan unit bisnis yang lain, khususnya apabila setiap unit bisnis tersebut memiliki tanggung jawab untuk menghasilkan laba, Singh (2008), Crawford (2009) Kepemimpinan transformasional berperan sebagai agen perubahan dalam penerapan knowledge manajemen (Alavi dan Liender, 1999) dan (Crawford, 2004:3)

\section{Pengaruh Knowledge Management Terhadap Inovasi}

Kaya et al. (2013) yang berjudul "The Impact of HRM Capabilities on Innovation Mediated by Knowledge Management Capability" menunjukan bahwa kemampuan manajemensumber daya manusia (HRM) berhubunganpositif dengan kemampuan knowledge management (KM) yang berubah menjadi inovasi. Program-program knowledge management biasanya terkait dengan tujuan organisasi dan diarahkan untuk meraih hasil spesifik, seperti berbagi kecerdasan, meningkatkan kinerja, meningkatkan keunggulan kompetitif, atau mendorong inovasi pada arah yang lebih tinggi seperti dikemukakan oleh Nonaka dan Takeuchi (1995), Al Ansari (2013), Samuel (2013), Reguia (2008). Knowledge Managament 
p-ISSN : 2655-7304

e-ISSN : 6655-8953

dengan representasi akusisi dan diseminasi dapat berpengaruh terhadap innovasi (Darroch, 2005).

\section{Pengaruh Inovasi Terhadap Daya Saing}

Modal manusia dan riset kreatif menurut Zemplinerová (2010) dan Autant Bernard (2001) dianggap sebagai faktor penentu yang paling penting dari inovasi . Adair ( 2004) menyatakanbahwa setiap organisasi yang inovatif harus memiliki seember ide. Menurut Košturiak \&Chal (2008), Skarzynski \& Gibson (2008), Tidd, Bessant \& Pavitt ( 2007) proses inovatif dapat dibagi menjadi dua bagian penting. Salah satu bagian inventif - terkait dengan generasidari ide asli, pikir atau konsep - dan yang kedua inovatif, di mana penemuan diimplemtasikan dan menjadi daya saing, (Ismail et al, 2009)

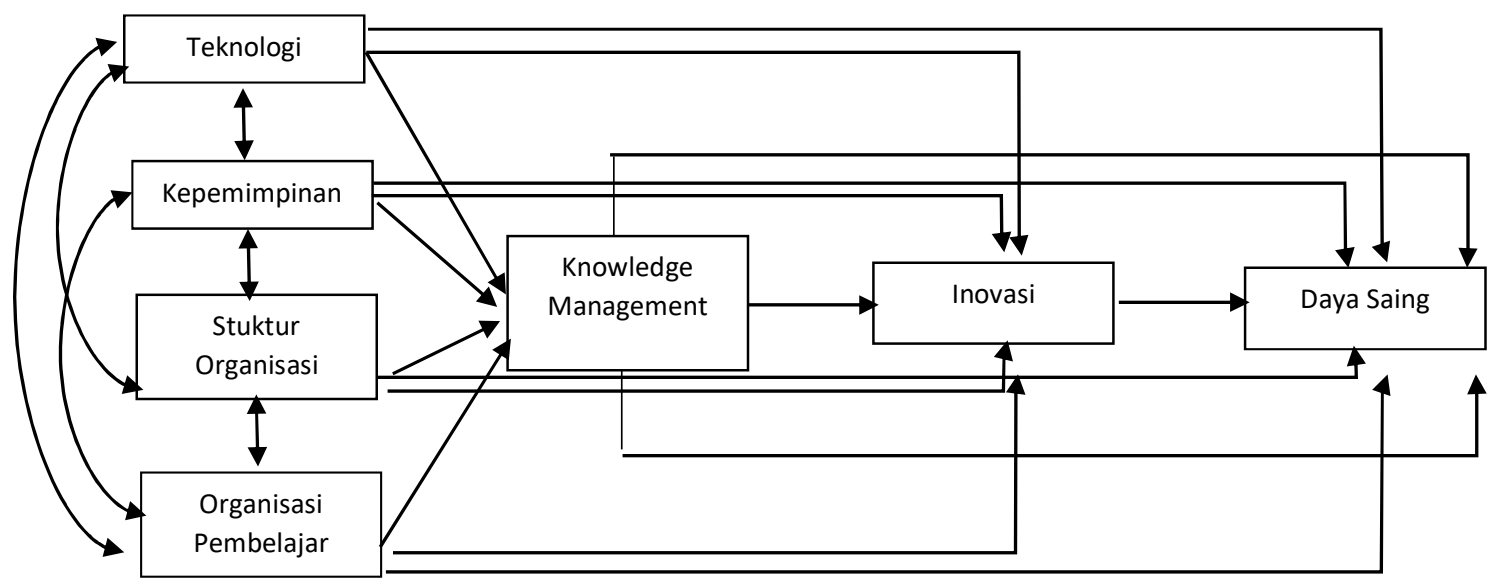

Gambar

Paradigma Model yang Ditawarkan

\section{KESIMPULAN}

Berdasarkan hubungan konseptual, maka dapat disimpulkan hubungan antar variabel secara teori sebagai berikut

1. Kepemimpinan, teknologi, organisasi dan organisasi pembelajaran secara simultan dan parsial berpengaruh terhadap Knowledge Management

2. Kepemimpinan, teknologi, organisasi dan organisasi pembelajaran mempunyai Hubungan antar Variabel.

3. Kepemimpinan, teknologi, organisasi dan organisasi pembelajaran berpengaruh secara simultan dan parsial terhadap Inovasi.

4. Knowledge management berpengaruh terhadap Inovasi

5. Inovasi berpengaruh terhadap daya saing

6. Knowledge management berpegaruh secara simultan dan parsial melalui Inovasi terhadap Daya saing

7. Knowledge management berpegaruh secara simultan dan parsial melalui Inovasi terhadap Daya saing

Oleh karena itu berdasarkan kajian teori sangat penting bagi IKM Batik untuk menerapkan manajemen pengetahuan, Orientasi kewirausahaan serta intelectual capital guna 
p-ISSN : 2655-7304

e-ISSN : 6655-8953

menumbuhkan organisasi pembelajar serta inovasi yang berdampak kepada peningkatan daya saing IKM. Dalam kondisi demikian IKM Batik dituntut untuk meningkatkan produksi, nilai ekspor, serta menyerap tenaga kerja

\section{DAFTAR PUSTAKA}

Abrahamson, E. (1991). Managerial fads and fashions: The diffusion and rejection of innovations. Acad. Management Rev. 16(3) 586-612.

Akamavi, N., and Kimble, C. (2005), Knowledge Sharing and Computer Supported CollaborativeWork: The Role of Organizational Culture and Trust, the University of York, Heslington,England

Alavi, M. \& Leidner, D. (2001). Knowledge Management and Knowledge Management Systems: Conception Foundations and Research issues. MIS Quarterly. 25(1): 107-136.

Alex M., (1998) Strategic Management, third edition, USA : Irwin McGraw-Hill, international edition.

Al-Mutawah, K.; Lee, V.; Cheung, Y. (2009) A new multi-agent system framework for tacit knowledge management in manufacturing supply chains. J. Intell. Manuf., 20, 593-610. 2.

Barney, J. B. (1991). Firm resources and sustained competitive advantage. Journal of Management, 17(1), 99-120

Bhat (2001) "Knowledge management in organizations: examining the interaction between technologies, techniques, and people", Journal of Knowledge Management, Vol. 5 Iss: 1, pp.68 $-75$

Blackwell, P., Shehab, E.M. and Kay, J.M. (2006), "An effective decision-support framework for implementing enterprise information systems within SMEs", International Journal of Production Research, Vol. 44 No. 17, pp. 3533-52

Carneiro (2000) How does knowledge management influence innovation and competitiveness. Journal of Knowledge Management Volume 4 . Number 2 . 2000 . pp. 87-98

Cerchione (2015). The Spread of Knowledge Management in SMEs: A Scenario in Evolution, Sustainability 2015, 7, 10210-10232

Choochote, K. ; Nurse, R. (2012). A Simple Knowledge Management Strategy Model for SMEs in Developing Countries.World Academy of Science, Engineering and Technology, International Science Index. Vol.64, 6(4), 159 - 163.

Davenport, T.H. \& Prusak, L. (1988), Working knowledge how organizations manage what they know. Boston, MA: Harvard Business School Press.

Darroch (2010) Knowledge management, innovation and firm performance, Emerald Group Publishing vol. 9 no. 3, pp. 101-115,

Dess, G.G., G.T. Lumpkin, dan J.G. Covin, 1997, “Entrepreneurial Strategy Making and Firm Performance: Test of Contingency and Configurational Models", Strategic Management Journal, Vol.18, No. 9, p. $677-695$ 
p-ISSN : 2655-7304

e-ISSN : 6655-8953

Desouza C.K. \& Awazu,Y. (2006), "Knowledge management at SMEs: five peculiarities", Journal of Knowledge Management, Vol. 10, No. 1, pp. 32-43.

Drucker, F. Peter (1985): Innovation and Entrepreneurship, Practice and Principles. Harper \& Row Publisher, New York.

Dyer, J.H.; Hatch, N.W. (2006) Relation-specific capabilities and barriers to knowledge transfers: Creating advantage through network relationships. Strateg. Manag. J. 27, 701-719. 3. Esper, T.L.;

Dudek (2013). Evaluation Of Knowledge Management In Small And Medium-Sized Enterprises. Polish Journal Of Management Studies vol 6 pp 168-174

Ellinger, A.E.; Stank, T.P.; Flint, D.J.; Moon, M(2010) . Demand and supply integration: A conceptual framework of value creation through knowledge management. J. Acad. Market. Sci. vol 38, 5-18

Evangelista P., Esposito E., Lauro V., Raffa M. (2010) "The adoption of knowledge management systems in small firms“, Electronic Journal of knowledge Management, Special Issue ECKM 2009, Vol. 8, Issue 1, pp.33-42

Hamel, Gary \& C.K Prahalad, 1994.Competing for the Future, USA : Harvard Bussiness School Press.

Hill Charles W.L. \& Jones R.Garret (2009) , Strategic Management Theory An Integrated Approach

Ismail et al (2010) Role of Innovation in SMEs Performance: A Case of Malaysian SMEs, Mathematical Methods in Engineering and Economics, pp 256-262

Julien, Ramangalah (2003). Competitive Strategy and Performance of Exporting SMEs: An Empirical Investigation of the Impact of Their Export Information Search and Competencies. Entrepreneurship: Theory and Practice 27(3):227 - 245

Kör (2013) The Relationship between Knowledge Management and Innovation International Journal of Business and Social Science Vol. 4 No. 4

Kenneth et al (2006)The Process of Innovation Assimilation by Firms in Different Countries: A Technology Diffusion Perspective on E-Business Management Science Vol. 52, No. 10, October 2006, pp. 1557-1576

Koruna, S., (2004). External technology commercialization-policy guidelines. International Journal of Technology Management 27 (2/3), 241-254

Kevin C. D. \& Awazu,Y. (2006), "Knowledge management at SMEs: five peculiarities", Journal of Knowledge Management, Vol. 10, No. 1, pp. 32-43.

MacKinnon, D., Cumbers, A. \& Chapman, K. (2002), "Learning, innovation and regional development: a critical appraisal of recent debates", Progress in Human Geography, Vol. 26, No. 3, pp. 293-311. 
p-ISSN : 2655-7304

e-ISSN : 6655-8953

Mundra, Neeru, Gulati, Karishma, Vashisth, Renu. (2011) Achieving Competitive Advantage through Knowledge Management and Innovation: Empirical Evidences from the Indian It Sector. The iup Journal of Knowledge Management, , vol. 9, no. 2, p. 7-26.

Meilhamil (2012). Switzerland Knowledge Management a way to gain a competitive advantage in firms, Hournal of International Letters of Social and Humanistic Sciences Vol. 14, pp 80-91

Megdadi, Ahmad S.M. Al-Sukkar, \& Mohammed A.J. Hammouri. (2012). Factors and benefits of knowledge management practices by SMEs in Irbed district of Jordan: An empirical study. International Journal of Business and Social Science,3(16), 325-331.

Nonaka, I. (1991). The Knowledge-Creating Company. Harvard Business Review, NovemberDecember: 96 - 104

Nonaka, I. (1994). A Dynamic Theory of Organisational Knowledge Creation. Organization Science, 5, (1): $14-37$

Nunes, M.B., Annansingh, F. \& Eaglestone, B. (2006), "Knowledge management issues in knowledge-intensive SMEs", Journal of Documentation, Vol. 62, No.1, pp. 101-119.

Porter Michael E (2008), Lima Kekuatan itu Bentuk Strategi, Bisnis Harvard Review, January

Prusak, L. and Weiss, L. (2007). Knowledge in organizational settings: how organizations generate, disseminate, and use knowledge for their competitive advantage. In Ichijo, K. and Nonaka, I. (Eds). Knowledge Creation and Management: new challenges for managers. Oxford: OxfordUniversity Press.

Robbins, Stephen P. (2006). Perilaku Organisasi. Edisi kesepuluh. Jakarta: PT Indeks Kelompok Gramedia

Rodríguez et al (2013) Knowledge Management and the Effectiveness of Innovation Outcomes: The Role of Cultural Barriers Antonio 22-23

Setyo Hari Wijanto, 2008, Structural Equation Modeling dengan Lisrel 8.8 - Konsep dan Tutorial, Graha Ilmu, Yogyakarta

Sparrow, J. (2001) "Knowledge Management in Small Firms", Knowledge and Process Management, Vol. 8, No 1, pp 3-16.

Sveiby, K. (1997) The New Organizational Wealth: Managing and Measuring KnowledgeBased Assets, Berret Koehler, San Francisco

Tan, N. L. (2011). Knowledge management acceptance: Success factors amongst small and medium-size enterprises. American Journal of Economics and Business Administration, 3(1), 73-80.

Tasmin et al (2010) Factors Influencing Knowledge Management Practices among Multimedia Super Corridor (MSC) organizations, BIMA Publishing Communications , pp 90-100 
p-ISSN : 2655-7304

e-ISSN : 6655-8953

Tjakraatmadja, JH dan Lantu DC. (2006), Knowledge Management dalam Konteks dan Organisasi Pembelajar. Bandung: ITB.

Thorgren, S., \& Wincent, J. (2011). Interorganizational trust: Origins, dysfunctions and regulation of rigidities. [Review]. British Journal of Management, 22(1), 21-41

Tobing L. P, (2007) Knowledge Management : Konsep, Arsitektur dan Implementasi, Yogyakarta : Graha Ilmu.

Toffler, A. (1980). The Third Wave: The Post Industrial Society, scientific-technological revolution, pp. 193-195.

Wheelen and Hunger, 2002, Management Stategic, Andi Offset Yogayakarta.

Wheelen, To, Hunger, David, 2010 ; Strategic management, Concept and Cases

Wigg, K. (1999). Knowledge management: An emerging discipline rooted in a long history. In C. Despres\& D. Chauvel (Eds.), Knowledge horizons: The present and the promise of knowledge management. New York, NY: Butterworth-Heinemann

Wiklund, J., \&Shepherd, D. (2003). Knowledge-Based Resources, Entrepreneurial Orientation, and the Performance of small and medium-sized businesses. Strategic Management Journal, 24, 1307-1314.

William (2009) Knowledge Management and Organizational Learning Annuals of Information Systems 4.

Wong, K.Y, Aspinwall, E. (2004) Knowledge management implementation frameworks: a review, Knowledge and Process Management, 11(2), 93-104.

-------------, (2005) Critical success factors for implementing knowledge management in smalland medium enterprises, Industrial Management \& Data Systems, 105:3, pp. 261-279

Zack, M.H. (2002, April). A Strategic Pretext for Knowledge Management. Paper presented at The Third European Conference on Organizational Knowledge, Learning and 38 Capabilities OKLC 2002. Athens, Greece.

Zieba, Zieba (2014) Knowledge Management Critical Success Factors and the Innovativeness of KIBS Companies, Inzinerine Ekonomika-Engineering Economics, 2014, 25(4), 458-465 